Peter Waldmann*

\title{
D La relevancia de la constitución durante la fase de la creación de los Estados Unidos y de los Estados latinoamericanos ${ }^{1}$
}

\section{Introducción}

Este ensayo tiene como tema la comparación del desarrollo que tuvieron los EE.UU. por un lado y los Estados latinoamericanos por otro durante el "largo" siglo XIX. Mientras que los EE.UU. se transformaron en el transcurso de ese siglo en una potencia mundial tanto a nivel económico como político y militar, las naciones latinoamericanas se hundieron en el caos de guerras civiles de las cuales lograron recuperarse sólo paulatinamente luego de haber alcanzado la independencia de España. Aun después de haberse consolidado como Estados en la segunda mitad del siglo, nunca llegaron a ser más que potencias de segunda categoría en el contexto internacional. El presente estudio parte de una doble hipótesis. Por una parte asumimos que ciertas condiciones estructurales, como por ejemplo la constelación existente en el momento de la creación de un Estado, tienen un efecto decisivo que se hace sentir mucho más allá de esa primera fase. En otras palabras, creemos que ciertas debilidades institucionales de los Estados latinoamericanos que pueden observarse hasta la actualidad se originaron en la época fundadora, al comienzo del siglo XIX. Por otra parte, planteamos la hipótesis más específica de que la forma de concebir la constitución y el trato que la constitución y las leyes reciben es una de las causantes del retraso del desarrollo de los Estados latinoamericanos.

Realizar una comparación entre América Latina y los EE.UU. bajo esta premisa encierra ciertos riesgos. Teniendo en cuenta la importancia positiva que la constitución federal de 1787 tuvo para el proceso de formación de la nación y del Estado en los EE.UU., corremos peligro de que -debido al contraste- la comparación con América Latina degenere en una enumeración de deficiencias y de "desviaciones" con respecto al modelo de Norteamérica. Además se podría cuestionar el uso generalizador de la palabra "América Latina". ¿No debería diferenciarse acaso entre Estados pequeños y grandes,

* Profesor de Sociología de la Universidad de Augsburgo, Alemania. Su área de investigación abarca temas de sociología política, cambio social, comportamiento desviante y violencia política.

1 Con este ensayo he pisado terreno que excede mis competencias científicas tanto en lo que se refiere a los conocimientos como sociólogo como con respecto a mi enfoque tradicional en América Latina. Esto se da por un lado al incluir una perspectiva histórica y, por otro, debido a las referencias que hace el análisis a los EE.UU. Por ello, recurrí al valioso apoyo y a los consejos recibidos entre otros de Knud Krakau, Michael Riekenberg, Hans Werner Tobler y Michael Zeuske. A todos ellos quiero expresarles en esta oportunidad mi agradecimiento. 
Estados ubicados en el centro de lo que había sido el imperio colonial de España y aquellos Estados que surgieron en las regiones periféricas de este mismo imperio? (Schroeter 1992). Además, en el caso de los EE.UU. se trata de una sola constitución, si no contamos las de los Estados integrantes de la Unión. Por el contrario, en América Latina, en el transcurso del siglo XIX se han redactado más de 100 constituciones (Loveman 1993: 368). ¿Cuál de ellas deberíamos utilizar para nuestros fines comparativos?

El autor es consciente de las dificultades que supone este análisis comparativo y reconoce que algunas de ellas son inevitables. Es difícil, por ejemplo, evitar que el proceso que llevó a la creación de la constitución en los EE.UU. aparezca a una luz más favorable que el mismo proceso en el sur del continente. Además cabe destacar que este tipo de comparación implica la necesidad de hacer simplificaciones y reducciones esquemáticas con respecto a la realidad. Si bien esto se debe, por un lado, a la lógica a la cual obedece esta forma de análisis, por otro, radica en el hecho de que el autor no está igualmente compenetrado con todos los casos estudiados. Pese a todas estas reservas, el autor apuesta por este análisis comparativo, ya que está convencido de que la comparación es el método más idóneo para sacar a la luz las características específicas del objeto estudiado. Esto es válido tanto para el estudio de las similitudes como de las diferencias (Nohlen 1994: 507).

Se prevén las siguientes etapas de investigación: primero se realizará una comparación entre las condiciones generales que rodearon la fundación de los EE.UU. y de los Estados latinoamericanos. Luego se analizará el proceso de emancipación de la metrópoli, que se presenta como un proceso doble tanto de rechazo como de continuación del legado colonial. La tercera parte enfoca la dimensión temporal en la cual se ubica la creación de un nuevo orden político. Además es necesario tener en cuenta el contexto social que acompañó el proceso de fundación del Estado. Cerramos el ensayo con una serie de consideraciones acerca de la diferente función que cumple la constitución en los EE.UU. y en América Latina.

\section{Condiciones generales}

No trataremos aquí de analizar los diferentes legados coloniales en cuanto a su cultura política (véase para ello el párrafo siguiente) sino que procuraremos investigar las circunstancias que incidieron de forma inmediata en el proceso de emancipación política y jurídica, sea que lo hayan agilizado o bien obstaculizado. Al comparar América del Norte y del Sur bajo esta óptica, resalta un factor que supera en importancia a todos los demás. Nos referimos a la medida en la cual el proceso de emancipación fue llevado a cabo de forma voluntaria.

Si diéramos crédito a lo que dicen los involucrados, las diferencias serían solamente pequeñas. Tanto en el norte como en el sur, los colonos afirmaban seguir siendo fieles súbditos de la respectiva corona y cumplir con sus obligaciones. Sostenían que ellos no habían cambiado de actitud, sino que, al contrario, el aumento de las obligaciones y de los controles por parte de la metrópoli los forzaba a concentrarse en mayor medida que antes en sus propios derechos e intereses. Sin embargo, estas explicaciones muy similares partían de situaciones y disposiciones muy distintas. En lo que se refiere a las colonias norteamericanas, se puede decir que había llegado el momento indicado para que se desligasen de la metrópoli (Heideking 1989a: 36; Adams 1973: 34). Varios pequeños 
levantamientos y acciones de protesta señalaban que ya se había generado un distanciamiento interno. Al menos la clase alta colonial estaba preparada a dar este paso decisivo. Por lo general, el pueblo tenía conciencia de encontrarse en una fase de cambios radicales en el ámbito político y de que se anunciaba un comienzo nuevo, y discutía abiertamente las diferentes opciones que se ofrecían.

La situación en América Latina era muy diferente, ya que ésta había sido impulsada forzosamente a independizarse por la crisis del Estado español (en concreto, por la ocupación de la Península Ibérica por las tropas napoleónicas). Seguramente en este caso tampoco faltaron expresiones de descontento dirigidas sobre todo contra el intento de Carlos III de disciplinar la administración (Fisher 1992: 43). A pesar de ello, los historiadores concuerdan en que nadie, tampoco en las zonas marginales del imperio colonial, cuestionaba seriamente la hegemonía de la corona española como tal (Bushnell 1985: 95; Halperín Donghi 1991: 90; para la zona de La Plata, Ferns 1973: 49) Por lo general, con la excepción de ciertos personajes marginales como Francisco Miranda (Lucena Salmoral 1992: 216), este paso no había sido considerado ni existía la predisposición para hacerlo. Fue la apatía de la monarquía española lo que obligó a la clase criolla, residente sobre todo en las regiones costeras orientadas hacia el comercio exterior, a encabezar y controlar el movimiento de independencia después de haber superado las dudas iniciales. Los conflictos armados y el clima general de inestabilidad política (Halperín Donghi 1991: 93) que se había apoderado del mundo occidental después de la Revolución Francesa pronto hicieron imposible el retorno a la tutela de la monarquía española y a la forma de gobierno monárquico en general. No quedaba otra opción que apostar por la independencia.

La estratificación social y étnica en las colonias latinoamericanas (Lynch 1985: 32) fue uno de los motivos principales por los cuales la clase gobernante criolla procuró evitar que el poder estatal permaneciese sin dirección durante mucho tiempo. Por cierto, también en las colonias británicas a lo largo del Atlántico existían diferencias entre la condición económica de la pequeña y pudiente clase alta y la del resto de la sociedad. Sobre todo en el sur, había una clara diferenciación entre los dueños blancos de las plantaciones y los esclavos negros. Sin embargo, el grueso de los colonos eran arrendatarios blancos y granjeros independientes con pequeñas y medianas propiedades. Por el contrario, en Sudamérica los criollos blancos constituían solamente una minoría en casi todas las posesiones de la corona española. Frente a ellos se encontraba una mayoría de mestizos e indios, mulatos y negros explotados social y económicamente. No es de sorprender que los blancos y sobre todo la clase alta criolla viviesen con el temor de que una disminución del control hegemónico diese pie a rebeliones por parte de las clases oprimidas y que esto generase una revolución social.

A ello se suman otras circunstancias que dificultaron el desarrollo armonioso del proceso de reestructuración política en Latinoamérica. Una de ellas era la inmensa extensión geográfica del imperio colonial de España. Debido a ello, las elites criollas y las sedes de los virreinatos tenían poco contacto entre sí y no pudieron ponerse de acuerdo para adoptar una actitud común al separarse de la metrópoli. Las capitales de los virreinatos resultaron ser un obstáculo para el sucesivo desarrollo político. La diferencia de poder y recursos entre estas capitales y el interior era tan grande que resultaba dificil unir ambas partes en el contexto de un Estado nacional. También representaba un problema el hecho de que, a diferencia de lo que sucedía en el norte, existían tres en vez de dos niveles que podían servir teóricamente como base territorial para la fundación de los nuevos Estados. Aparte de 
las provincias y las unidades territoriales de tamaño mediano (los posteriores Estados nacionales) basadas en gran medida en las llamadas "audiencias" o las capitanías generales de la época colonial, se barajaba inicialmente la posibilidad de considerar toda la América española como una nación unida bajo un solo Estado (Chiaramonte 1986; Criscenti 1961).

Con respecto a todos estos puntos, los fundadores de los EE.UU. tenían claras ventajas con respecto a las elites criollas. Las colonias inglesas eran relativamente pequeñas si las comparamos con las enormes extensiones de América Latina. Es precisamente por ese motivo que desde temprano se estableció el contacto entre los grupos dirigentes de las diversas colonias. No había metrópolis que oprimieran el interior y el proceso de fundación del Estado se limitó desde el principio a la alternativa de distribuir el poder entre varios Estados separados o de dar prioridad a la unión de éstos en uno solo.

Sin embargo, había también una serie de problemas que dificultaron el proceso de fundación del Estado tanto en el norte como en el sur. En ambos casos fue sólo una minoría la que participó activamente en el movimiento independentista. Por ello, era necesario encontrar la forma de interesar a la mayoría en el proyecto de la independencia. En este sentido, en ambas partes de las Américas las guerras de independencia desempeñaron un rol importante, ya que conmovieron a grandes sectores poblacionales y desencadenaron olas de movilizaciones sociales y geográficas. Las guerras, sobre todo las guerras anticoloniales, adquieren una dinámica propia que puede exceder las metas a las cuales los iniciadores habían apuntado inicialmente. Tanto en América del Norte como del Sur era necesario impedir que las tendencias radicales adquiriesen demasiada fuerza y dificultasen o entorpeciesen la transición controlada hacia un nuevo orden político. $\mathrm{Al}$ final de las guerras de independencia y de las civiles, tanto las elites del norte como las del sur se encontraron con que sobre los nuevos Estados pesaba la hipoteca de que sus países estaban desangrados y pobres, y el tesoro nacional completamente endeudado.

\section{La dialéctica del proceso de emancipación}

La relación con las metrópolis respectivas continuó siendo ambivalente y tensa aun después de finalizadas las guerras de independencia. Por un lado existía el afán de obtener autonomía política unido a cierto distanciamiento del modelo estatal impuesto por el poder colonial, al que se le reprochaba abuso de poder e incapacidad. Por el otro, resultaba inevitable incorporar a la nueva estructura estatal ciertos elementos institucionales de la propia historia colonial, elementos que a la vez eran parte de la tradición compartida con la metrópoli. Esta dialéctica de distanciamiento intencional y a la vez de conservación de ciertas costumbres políticas heredadas es un fenómeno que encontramos tanto en América del Norte como del Sur. Además del clima ideológico de la época y de las experiencias hechas en la guerra civil, es éste un factor determinante en los contenidos de las nuevas constituciones y de su aplicación en la práctica.

J. Heideking ha observado que la constitución federal de los EE.UU. representaba en muchos sentidos la antítesis de la del Estado británico. En aquella época, éste era el Estado europeo más desarrollado en términos económicos gracias a la existencia de organismos burocráticos sumamente eficientes, como por ejemplo el Banco Central, y de un cuerpo militar profesional así como de un Parlamento que estaba a cargo de todas las decisiones políticas (Heideking 1999a: 2). El desarrollo acaecido en la metrópoli la había 
transformado en un impressive fiscal-military state, lo cual para los colonos implicaba la traición de las virtudes británicas originales y era interpretado como señal de decadencia política. A la hora de fundar sus propios Estados, los colonos adoptaron posturas inspiradas por una actitud de oposición que rescataba, a veces intencionalmente, elementos de constituciones premodernas (Mann 1993: 143; Adams 1973: 25; sobre todo Heideking 1999a: 6 y 10). Entre estos elementos cabe mencionar la restricción del poder estatal por un sistema elaborado de checks and balances que más tarde fue complementado por un catálogo de derechos fundamentales. Otro elemento era la restricción de las competencias que el Estado federal tenía con respecto a cada uno de los Estados miembros, así como la intención general de impedir la creación de una burocracia demasiado poderosa. En vez de mantener un ejército permanente, se prefirió delegar la responsabilidad de la defensa nacional a las milicias de los Estados miembros; finalmente cabe mencionar la gran importancia que se le asignaba al pueblo y a la opinión pública como garantes del carácter democrático de la toma de decisiones políticas.

A pesar de todos estos nuevos (o aparentemente "viejos") acentos que distinguían la constitución norteamericana de la de la metrópoli -de la que nunca había existido un texto escrito-, debemos recordar que la constitución de los EE.UU. fue creada y promulgada aplicando en gran medida procedimientos y reglas que el poder colonial había introducido o aprobado, es decir que ya habían sido practicados mucho antes de la independencia (Stourzh 1984; Adams 1973: 30; Mann 1993: 137). Por ejemplo, ya desde hacía tiempo existía la tradición de crear versiones escritas de las leyes importantes (charters); además, los ciudadanos estaban acostumbrados a manifestar sus opiniones en reuniones políticas, a enviar delegados para que participasen en los gremios, a aceptar la toma de decisiones por voto mayoritario y a convencer a la oposición con argumentos en vez de emplear armas para acallarla. Desde este punto de vista, la revolución no significó una ruptura completa con el pasado y con los principios que habían tenido validez durante la época colonial, más bien los radicalizó aplicando ciertos elementos de la democracia de base, como las reuniones municipales.

Ya desde el inicio, la situación en América Latina fue más compleja y multifacética que en los EE.UU. Al principio, esto se debía por un lado sobre todo al abandono involuntario de la tutela que había brindado la corona española. Por otro, era la consecuencia de un proceso político que se había producido en la metrópoli, en cuyo transcurso las fuerzas liberales se impusieron temporalmente. Nos referimos a la Junta de Sevilla y luego a las Cortes de Cádiz, cuyas propuestas liberales ejercieron una influencia decisiva sobre las constituciones de los países latinoamericanos (Rodríguez 1998). Sin embargo se puede constatar que por lo general predominaba en Sudamérica la ley de la "imitación mediante la oposición". Se acentuaba la soberanía jurídico-estatal recién adquirida a través de un distanciamiento enfático con respecto a los elementos autoritarios y corporativos que habían caracterizado el régimen colonial de España (Lechner 1992: 72). Esta reorientación progresiva se manifestó en una serie de medidas relativas a los principios de soberanía del pueblo y división de poderes que fueron incorporadas a todas las constituciones y que se referían sobre todo a los siguientes aspectos: la abolición del comercio de esclavos, el establecimiento del derecho a nacer libre ${ }^{2}$, la abolición de la Inquisición y

2 Por lo general, no se abolió la esclavitud. Los negros seguían apostando preferentemente por el prolongado servicio militar para adquirir la libertad (Bushnell 1985:121). 
la restricción de los derechos del clero y la Iglesia, la abolición de los títulos de nobleza y de los privilegios para primogénitos, la libertad de desplazamiento y de expresión, la protección de la propiedad privada, la igualdad de los ciudadanos ante la ley y el derecho al voto, fuera éste general o limitado por criterios de propiedad (Halperín Donghi 1991: 113; Bushnell 1985: 110, 188, 129).

Sin embargo, encontramos referencias en la literatura que nos indican que el principio de igualdad de los ciudadanos ante la ley no contaba por completo con el apoyo de las clases media y alta criollas, mientras que los derechos de libertad sí disfrutaban de una aceptación general (Lynch 1985: 47). Debido a un sentimiento de superioridad o bien de desconfianza frente a las capas sociales bajas y de piel oscura (Loveman 1993: 65), el sector criollo se limitaba frecuentemente a avalar el principio de la igualdad sólo de forma retórica, sin considerar seriamente su puesta en práctica. Por lo general, las nuevas constituciones se veían afectadas por el hecho de no ser seriamente aplicadas en la vida política. No bien habían sido creadas y promulgadas sucumbían ante nuevas leyes o a la fuerza bruta. Esto se debía, entre otras cosas, al hecho de que las elites latinoamericanas carecían de experiencia práctica en cuanto a procedimientos de democracia y de autoadministración en general. Las reformas borbónicas de la segunda mitad del siglo XIX, que habían sido inspiradas por una orientación más liberal en lo que al comercio se refiere y por el afán de aumentar la eficiencia administrativa, habían generado una disminución de los criollos en los cargos responsables de la administración colonial. Ellos tenían sólo la posibilidad de elegir representantes en el ámbito municipal. Como consecuencia, los concejos municipales fueron los primeros en intentar sustraerse al control del régimen colonial (Halperín Donghi 1991: 100; Bushnell 1985: 95; Ferns 1973: 73).

En esta circunstancia reside la enorme diferencia que existe entre las condiciones iniciales de los movimientos de independencia de América del Norte y del Sur ${ }^{3}$. Por un lado, los grupos que en el norte se habían rebelado contra el régimen colonial ejercían cierta influencia sobre la forma de organización del Estado y los principios de distribución de poderes. Por otro, podían recurrir a reglas probadas y establecidas desde la época colonial, tales como la formación de mayorías y la compensación de intereses para garantizar la aceptación general de su propuesta e impedir conflictos explosivos. La situación en América Latina era diferente, ya que las elites criollas tenían que enfrontarse con dos situaciones desconocidas: primero porque se hallaban ante la necesidad de dotar a los Estados emergentes de una base de legitimación nueva (la soberanía del pueblo, la división de poderes, etc.), y segundo porque ratificaron e implementaron este nuevo orden recurriendo a las reglas democráticas que el mismo postulaba. Esta doble dificultad exigía demasiado a los Estados emergentes y sus elites.

Las consecuencias provocadas por las diferentes condiciones iniciales se manifestaron rápidamente. En el fondo, estas consecuencias no han sido superadas hasta el día de hoy. En lo que a los EE.UU. se refiere, la aprobación de la constitución federal resultó ser una base sólida para el desarrollo político y social que siguió pese a los serios conflictos sociales que lo acompañaron y a la casi quiebra de la unión nacional (la Guerra de

No profundizaremos aquí en qué medida las posibilidades de desarrollo de un Estado que es producto de un movimiento de independencia han sido influenciadas por el hecho de que el movimiento se haya dirigido contra una metrópoli decadente o próspera. 
Secesión de los años sesenta). En tiempos recientes se ha señalado repetidamente el potencial dinámico que tienen estos elementos premodernos de la constitución estatal y social de los EE.UU. (Heideking 1999a: 10). Efectivamente, estos rasgos, que en épocas de incontestada soberanía estatal parecían anticuados y contrarios al progreso, en una época como la actual que se suscribe a la desregulación y la desburocratización se convierten en ventajas para el desarrollo. Nos referimos a rasgos tales como la descentralización y el federalismo de los EE.UU., el predominio de la confianza general en las capacidades de iniciativa del ciudadano sobre la que se deposita en mecanismos autoritarios de control y la división estricta entre las esferas política y religiosa. De esta forma, el ámbito religioso, que tiende a perder credibilidad en los sistemas democráticos, ha podido conservarla allí. Esto explica también la vitalidad inquebrantable de la vida religiosa en los EE.UU.

Ya hemos constatado la incapacidad que manifestaron las elites criollas no sólo para formular constituciones republicano-liberales sino también para implementarlas en la práctica respetando justamente esos principios republicanos. En la historia de los Estados latinoamericanos abundan los textos constitucionales elegantemente redactados (Garzón Valdés 1999). Por otra parte, con el transcurso del tiempo se establecieron ciertas prácticas que los contradecían, tales como la posibilidad de limitar por ley los derechos constitucionales, la de dotar al poder ejecutivo de poderes especiales con cierta facilidad jurídico-administrativa y la ausencia casi completa del control civil sobre el ejército. Sin embargo, en lo esencial, las elites criollas se atuvieron a su plan inicial de combinar el paso hacia la independencia política con la transición hacia un sistema de Estado republicano liberal. El problema principal no eran tanto las constituciones en cuanto tales sino más bien la falta de energía con la que fueron aplicadas en la realidad. En la práctica permanecieron vigentes reglas muy diferentes de las estipuladas en la constitución, prevaleciendo el espíritu de intolerancia y particularismo sin restricciones, así como el ansia de poder sin respeto por las barreras impuestas por las leyes ${ }^{4}$. En la historia latinoamericana, sobre todo de la primera parte del siglo XIX, abundan las guerras civiles, los conflictos entre bandos, los golpes de estado exitosos y fracasados, las rebeliones y las revoluciones de palacio.

La incorporación a las constituciones de principios y decretos sin correspondencia alguna en la práctica originó una permanente ambigüedad y doblez en el discurso político y jurídico que tuvo consecuencias fatales a largo plazo. A esto se refiere Octavio Paz al afirmar que los latinoamericanos emplean con mucha naturalidad la mentira, y también la aseveración de Brian Loveman que establece una conexión directa entre la constitución y la tiranía (Gumucio 1987: 122; Loveman 1993). Por un lado, estas constituciones proclamaban la libertad de opinión política, por otro, en muchos Estados era uso

4 No siempre se condenó el hecho de que el Gobierno no respetara las leyes y ejerciera sus poderes de forma autoritaria. Al contrario, frecuentemente esto era considerado como la única forma viable de garantizar la seguridad y el orden en la sociedad. La justificación clásica de este estilo gubernamental proviene del venezolano L. Vallenilla Lanz (Cesarismo democrático, primera edición 1919). Los representantes exitosos y más recientes del bonapartismo plebiscitario son G. Vargas y J. D. Perón. Es sólo desde la reciente ola de democratización de los años 80 que el modelo del Estado de derecho liberaldemocrático es considerado en forma general como el único modelo estatal viable. Para mayor información sobre las ideologías de Estado autoritarias véase Waldmann (1971). 
perseguir a la oposición de la forma más cruel. Por un lado, la constitución exigía la división de los poderes, por otro, el Gobierno imponía su voluntad pasando por encima del Parlamento y del poder judicial. Por una parte, los Estados se adherían al principio de la libertad religiosa, por otro declaraban el catolicismo como religión del Estado. Podrían mencionarse un sinnúmero de otros ejemplos (Loveman 1993: 60). Siguiendo al filósofo británico del derecho H. L. A. Hart puede decirse que en el fondo no existía (y en muchos casos sigue sin existir) una regla obligatoria que definiera cuál era la norma jurídica vigente y cuál no (Hart 1961: 77 y 92). Sobre todo la llamada economía institucional ha puesto de manifiesto en qué medida este defecto puede frenar el desarrollo económico de un país (para América del Norte véase North 1983).

\section{Constituciones: creación de orden y de mitos}

Los procesos que conducen a la creación de una constitución pueden variar en el tiempo. En algunos Estados latinoamericanos se promulgaron constituciones en serie (el caso extremo es Bolivia con un total de 14 constituciones promulgadas entre 1825 y 1957; véase Garzón Valdés 1999: 113). Esto puede interpretarse como experimentos en busca de la "verdadera" constitución. Por el contrario, en los EE.UU. los fundamentos constitucionales del nuevo orden político se establecieron en un lapso de tiempo corto. La Convención de Filadelfia y la consiguiente ratificación de la constitución federal por parte de los Estados miembros, y por último la primera enmienda de 1791, que sancionó los derechos fundamentales, dieron fin (por lo menos en forma provisoria) al proceso de creación del nuevo Estado, un proceso que se había iniciado con la proclamación de la independencia en 1776 (Lutz 1988: 96). La entrega pacífica del poder gubernamental a la oposición diez años después confirma que la constitución funcionaba. Este transcurso comprimido tuvo muchas ventajas comparado con la provisoria situación jurídica y política en la cual se encontraron muchos Estados latinoamericanos hasta mediados del siglo, pues redujo los costos militares y económicos de la transición de un orden a otro, impidió que la violencia se desbordara y brindó excelentes oportunidades para la creación posterior de mitos que fundamentaran la identidad nacional.

Para poder apreciar adecuadamente las ventajas prácticas que conlleva la substitución acelerada del orden viejo por uno nuevo hay que tener en cuenta que el proceso de emancipación, tanto en América del Norte como del Sur, se dividió en casi todos los casos en dos fases. En la primera fase, la independencia del poder colonial era claramente prioritaria; el discurso constitucional hacía hincapié en la libertad y en la formación de una voluntad política autónoma. En la segunda fase, predominó la preocupación por el nuevo orden estatal. ¿Cómo debía diseñarse el nuevo Estado para garantizar la convivencia estable y satisfactoria de los diferentes grupos sociales? Si la primera fase se caracterizó por tendencias particularistas y separatistas, en la segunda se destacaban las propuestas constructivas que apuntaban a la creación de una organización estatal capaz de funcionar y de representar los intereses generales. Respecto del transcurso de ambas fases se pueden constatar enormes diferencias entre los EE.UU. y la mayoría de los Estados latinoamericanos.

En los EE.UU., la guerra de la independencia -la "revolución" contra la metrópolitambién desencadenó fuertes tendencias centrífugas. En reacción a la "tiranía" británica, 
muchas personas se sintieron más atraídas por la idea de conformar una asociación laxa de varias sociedades de tamaño limitado y estructuradas de forma igualitaria que por la propuesta de fundar un Estado compacto (Mann 1993: 155). A estas tendencias de descentralización se oponía la posición adoptada sobre todo por A. Hamilton, quien reclamaba la creación de un Estado federal que tuviese los recursos necesarios para actuar tanto hacia fuera como hacia dentro. Según Hamilton, el Estado federal debería estar dotado de un cierto grado de poder y de instituciones centrales eficientes para poder abarcar y contener todos los Estados miembros. La constitución recogió ambas tendencias. Los constituyentes lograron reconciliar las fuerzas antagónicas, representativas de las dos fases, evitando una crisis de autoridad política (Adams 1973: 39).

Al tornar la mirada a América del Sur, se evidencia el logro que supuso esta síntesis obtenida en tan poco tiempo. En el caso latinoamericano también se produjo una transición sin fricciones, pero no entre la fase de separación de la metrópoli y la de renovación del Estado sino entre la guerra de la independencia y las guerras civiles que la sucedieron $^{5}$. Los conflictos internos en torno a la futura estructuración del subcontinente ya habían surgido con vehemencia durante las luchas contra la corona. Una vez lograda la liberación de toda Sudamérica de la hegemonía española, continuaron con la misma fuerza. Lo que cambió fueron frecuentemente los objetos del conflicto y los frentes político-militares. En parte las pugnas se referían a reclamos territoriales y en parte a principios jurídicos o a la cuestión de cómo estructurar el Estado. En algunos casos se trataba de intereses económicos, como, por ejemplo, la alternativa mercado libre o protección de la industria nacional; en otros, se disputaban rivalidades personales con medios militares. Intentos ocasionales por parte de los diferentes partidos de ganarse el apoyo proveniente del extranjero (sobre todo el del influyente imperio británico) complicaban adicionalmente la situación (Buisson 1992; Bushnell 1985; Lynch 1973).

Las tensiones principales surgían por lo general entre dos grupos: por un lado las elites de las capitales de los antiguos virreinatos, por otro, los dirigentes de las milicias locales o las familias influyentes de ciudades pequeñas. Basándose en las fronteras coloniales, los primeros pretendían crear un Estado nacional de gran superficie, mientras que las elites locales buscaban intensificar el proceso de fragmentación política de manera que la provincia o región fuese la unidad básica del nuevo orden político. Gracias a su habilidad militar y a su iniciativa política, los líderes locales lograban movilizar a menudo a un nutrido número de seguidores. Esta época de inseguridad interna y de permanentes guerras entre bandos es recordada en muchos países como la época del caudillismo (Waldmann 1978: 191). Durante mucho tiempo los caudillos lograron impedir que las elites capitalinas extendiesen su hegemonía a la región que rodeaba estas ciudades ${ }^{6}$. La idea de crear un territorio nacional volvió a cobrar fuerza sólo a partir de la mitad del siglo junto con el modelo de desarrollo orientado hacia la exportación. Los pioneros de

5 Una excepción a esta regla la constituye el caso de Chile, donde después de la fundación del Estado no se asistió a mayores turbulencias políticas sino al Gobierno estable de Diego Portales. La constitución de 1833 fue el fundamento de ello. Asimismo, en Venezuela, la constitución de 1830 brindó las condiciones necesarias para permitir que el Gobierno de José Antonio Páez se desarrollase durante 18 años con bastante estabilidad.

$6 \quad$ No debe sobrestimarse el contraste entre las elites urbanas y los caudillos. En varios casos, las elites urbanas recurrían al apoyo de un caudillo para garantizar el orden y la seguridad pública. 
la consiguiente fundación de un Estado nacional fueron en muchos casos caudillos que ejercían el poder incontestado sobre grandes territorios luego de haber derrrotado a todos sus rivales.

El papel que desempeñaron las guerras (tanto las de independencia como las civiles) en este proceso es importante, ya que de ellas surgieron las condiciones, difíciles de corregir, para la creación de la constitución y la organización del Estado. Al respecto no deberían sobrestimarse las diferencias entre América del Norte y del Sur. En épocas de nacionalismo, las guerras suelen ser fuentes de cambios difícilmente predecibles y controlables. Movilizan a grandes cantidades de personas que, arrancadas de su contexto cotidiano, se ven ante la nueva posibilidad de mejorar su condición de vida mediante el uso de la violencia. La movilización militar de grandes masas de gente produce por lo general una presión democratizadora difusa que pone en cuestión las instituciones tradicionales y los órganos de representación. En todos estos aspectos, América del Norte y del Sur tienen muchas similitudes (Halperín Donghi 1991: 120; Heideking 1999b). Lo que las diferencia son las consecuencias que tuvieron las guerras, siendo decisivo el hecho de que la de las colonias británicas haya sido de corta duración.

Además de los ejércitos regulares, había en América del Norte una serie de guerrilleros y de milicias formadas espontáneamente que luchaban por cuenta propia (Heideking 1989b: 39, 1999). Sin embargo, éstos nunca cuestionaron la autoridad de las fuerzas armadas regulares de G. Washington, es decir que nunca pusieron en duda los principios fundamentales de ordenamiento militar. Con sus persecuciones y acciones propagandísticas las unidades irregulares contribuyeron de manera decisiva a la difusión del pensamiento patriótico (Heideking 1999b: 137). Su agitación era por un lado una advertencia a las clases altas de las colonias de que tomasen en serio la opinión pública y fuesen flexibles en asuntos sociales. Por otro, estas movilizaciones y otros pequeños levantamientos (sobre todo la Shay-Rebellion) que tuvieron lugar después de la guerra, eran interpretados como señal de que las corrientes democráticas de base podían descontrolarse fácilmente y transformarse en una anarquía general o en una revolución social. La constitución federal de 1787 tuvo en cuenta estas dos lecciones. Gracias a la aceptación general que recibió, la misma pudo intensificar el impulso emanado del movimiento de independencia hacia el fortalecimiento del proceso de concientización e integración nacional. El precio, sin embargo, fue la exclusión de ciertos problemas imposibles de resolver en el debate constitucional, como la esclavitud. De esta forma se impidió la continuación inmediata de la lucha que podría haberse producido en ese momento entre las propias colonias. A pesar de ello, a largo plazo la guerra civil resultó ser inevitable.

El caso contrastante de América Latina demuestra que los Founding Fathers de la constitución norteamericana tomaron la decisión correcta al intentar impedir la generación de conflictos internos (aunque entonces ciertos asuntos delicados sólo hayan sido postergados y no resueltos). En América del Sur, por lo general no se logró frenar las fuerzas anárquicas y destructivas que habían desatado las guerras de independencia. La violencia se incrementó, destruyó las instituciones estatales y no dejó intacto un solo ámbito, generando una situación que, al estilo de Hobbes, ha sido descrita como lucha de todos contra todos (Halperín Donghi 1991: 155; Ferns 1973: 76). Sólo a partir de la mitad del siglo se calmaron las olas de violencia. Los cortos y pasajeros períodos de paz en ciertas regiones no fueron el resultado de la restauración del respeto a la ley, sino que se debieron a que algún poderoso consiguió controlar a sus adversarios y mantenerlos a 
raya mediante el uso de la violencia. Las turbulencias sangrientas que se prolongaron durante varias décadas han marcado a los países latinoamericanos de forma duradera y determinante. La economía quedó arruinada, la población dramáticamente empobrecida y el tesoro nacional completamente endeudado (Bushnell 1985: 150; Lynch 1973: 338). La degeneración de las costumbres generales y de la cultura política constituyó un legado particularmente problemático que hizo necesaria la presencia permanente del ejército en la vida política (Loveman 1993: 63). Tal como lo indica M.S. Ferns, a partir de ese momento, siempre han existido dos escenarios de disputa política en los cuales un político ambicioso tiene que saber moverse. Uno es la plataforma civil, el otro, la militar (Ferns 1973: 65). La posición privilegiada asignada al ejército se evidencia en las constituciones promulgadas a partir de los años 30, que mantuvieron un carácter esencialmente republicano pese a su orientación generalmente conservadora (Romero 1969: 140; Halperín Donghi 1991: 210).

Además de los daños económicos y políticos generados por las guerras civiles en América del Sur, es necesario destacar los "simbólicos". Constituyen una época oscura que ha sido generalmente borrada de la conciencia pública y pasada por alto en la historiografía de muchos países latinoamericanos (Riekenberg 1995: cap. 2 y 4). Se suelen vincular los comienzos de los movimientos de independencia en 1810 directamente con los procesos de formación estatal y nacional que se iniciaron sólo a partir de la mitad de siglo como si no existiese una brecha entre estas dos fases. Los testigos intelectuales de la época y los dirigentes políticos con visiones a largo plazo quedaron amargados y resignados ante las incesables luchas. Se dice que S. Bolívar, el gran libertador, comentó antes de morir que no se había conseguido nada más que la libertad (Lynch 1973: 335). Este escenario contrasta claramente con el de los EE.UU. donde, pocos años después de haber terminado exitosamente la guerra de independencia, la promulgación de la constitución federal fue celebrada como el momento culminante del movimiento de la independencia y como la verdadera hora de nacimiento del nuevo Estado. Aquí radican los motivos por los cuales en los EE.UU. existe una relación muy estrecha y casi religiosa entre el sentimiento nacional y el constitucionalismo. Asimismo, esto explica la voluntad inquebrantable que existe en América del Norte de explorar y reinterpretar en cada fase histórica los principios centrales de la constitución norteamericana y de asignar tanta importancia a la "cultura legal" (Vorländer 1989: 69).

\section{El contexto social}

En su obra La democracia en América, redactada en los años 30 del siglo XIX, A. de Tocqueville, señaló repetidamente la importancia que tienen las "costumbres" para el funcionamiento de la democracia en los EE.UU. (Tocqueville 1976: 332). Según el científico y político francés, la opinión pública era tan importante como las leyes. Tocqueville se admiraba del alto nivel de educación que los americanos tenían con respecto a asuntos de importancia general aun en las regiones más remotas de este país, poco desarrollado en ese entonces. Alababa a las mujeres por ser importantes fuentes de apoyo a la moral y a la familia. Además, recalcaba las ventajas de la gran difusión de la religiosidad ya que ponía límites a la ambición exagerada de enriquecerse constituyendo por ello un requisito indispensable para garantizar el funcionamiento de las instituciones republica- 
nas. Tocqueville llegaba a la conclusión de que el Estado democrático era exitoso en los EE.UU. porque estaba fundamentado en el pensamiento y la actuación de los ciudadanos. En la misma época, un grupo de intelectuales argentinos jóvenes, conocidos como la Generación de 1837, decidía estudiar con detalle la realidad social de su país antes de hacer una propuesta para la nueva constitución nacional (Romero 1969: 134). Este grupo se encontraba bajo la impresión del desarrollo oscilante entre la dictadura y la anarquía en la región del Plata y estaba influenciado por el pensamiento de la escuela de derecho alemana, sobre todo por F. C. von Savigny. Partía de la convicción de que era necesario adaptar las leyes provenientes de otro Estado a las condiciones sociales del país nuevo antes de implementarlas. ¿Cuál era la realidad en el norte y en el sur de América? ¿Existía correspondencia o divergencia entre las normas y estructuras sociales por un lado y el modelo estatal por otro a la hora de implementar las nuevas constituciones?

Si tratamos de contestar esta pregunta en el caso de las colonias británicas de América del Norte, se puede constatar que la mayoría de las observaciones y reflexiones hechas por Tocqueville pueden ser aplicadas retrospectivamente a la fase de fundación del Estado norteamericano. Las investigaciones relevantes nos indican que al comienzo de la guerra de independencia las colonias ya constituían esencialmente una nación, es decir se caracterizaban por un alto grado de homogeneidad sociocultural y madurez política (Mann 1993: 137; Stourzh 1965: 254; Tobler 2000: 56). Existían por cierto culturas regionales y locales parcializadas y había tensiones, por ejemplo, entre el sur, cuya economía estaba basada en la esclavitud, y el norte, que la rechazaba. Asimismo, la ética de igualdad y bienestar común de las comunidades predominantemente rurales en la llamada "frontera" contrastaba con la ambición individualista de riqueza y ascenso social que era típica de las grandes ciudades del este. Sin embargo, predominaban por lo general los factores integradores que proporcionaban una base de intereses y valores compartidos. Entre ellos cabe mencionar el alto ingreso per cápita promedio, un alto grado de alfabetización debido a la religiosidad generalizada (lectura de la Biblia), así como la distribución relativamente equilibrada de bienes e ingresos. El carácter esencialmente democrático de la sociedad colonial se expresaba también en el hecho de que en ella tenía derecho a votar un porcentaje más elevado de la población que en la metrópoli (Stourzh 1984: 164).

Eran dos los grupos que constituían los pilares de esta sociedad. Uno era la capa compuesta de pequeños y medianos granjeros y completada por artesanos y comerciantes urbanos. El otro era la pequeña clase alta de los llamados notables que descendían de las familias tradicionales de las colonias y que además de poseer grandes extensiones territoriales desempeñaban un oficio como comerciantes o abogados.

La sociedad norteamericana estaba compuesta sobre todo por granjeros que se dedicaban a la producción capitalista. Éstos constituían, junto con la clase media urbana, alrededor del 90\% de la población blanca (Tobler 2000: 56). Esta masa de colonos rurales que compartían intereses similares así como ciertos valores y actitudes constituían un grupo social con un gran potencial de poder. Junto con la baja clase media urbana que se articulaba sobre todo en los llamados town meetings, este grupo tenía influencia decisiva en la opinión pública, la cual fue cobrando cada vez más importancia durante la fase de la emancipación y de la creación del Estado. El contrapeso estaba por lo general formado por los notables, descendientes de las familias coloniales tradicionales que habían liderado e ideado el movimiento de independencia dotándolo a la vez de una base filosófica y teórica. También en este caso se trataba de un grupo relativamente homogéneo estrecha- 
mente vinculado por contactos amistosos o lazos familiares más allá de los límites coloniales, y cuyos miembros destacados habían recibido una formación humanista además de jurídica en muchos casos (Mann 1993: 148). Mientras que los granjeros representaban el elemento democrático igualitario de la revolución (incluyendo las visiones radicales de redistribución en los sectores inferiores de esta clase), las familias de notables, pese a su receptividad en lo relacionado a un orden que pusiera límites al poder estatal, confiaban más en minorías formadas e instruidas para tomar las decisiones adecuadas respecto del bien común y la protección de sus intereses como propietarios (Gargarella 2000). La relación dialéctica que suponía tanto la generación de tensiones como de compromisos mutuos entre los dos grupos claves de la sociedad dotó de un elemento específico a la revolución y al proceso que condujo a la creación del nuevo Estado, aunque cabe destacar que este proceso nunca escapó al control de la capa que había sido tradicionalmente dominante.

Pese a que esta descripción resulta un tanto simplificadora ${ }^{7}$, alcanza para evidenciar hasta qué punto la situación social era diferente de la que reinaba en América Latina. Hay que recordar una vez más que en la época en que las tropas napoleónicas invadieron la Península Ibérica, en América Latina nadie pensaba seriamente en denegar la lealtad a la corona española. La sociedad criolla estaba demasiado fragmentada y dividida en ese momento como para que fuera posible un proceso de concientización y de generación de voluntad nacional. Debido a las grandes distancias geográficas que existían entre los importantes centros urbanos, las clases altas no tenían prácticamente contacto entre sí. Además, las diferencias entre los centros urbanos y las zonas rurales cercanas y remotas eran tan grandes con respecto al nivel de educación y a las percepciones y costumbres cotidianas que se podría decir que la gente vivía prácticamente en dos mundos diferentes. Sólo en los niveles local y regional había intentos que apuntaban hacia la generación de una conciencia colectiva (Bushnell 1985: 116, 148; Romero 1969: 101). Fuera de estas "patrias chicas" no existía un sentimiento nacional extendido que hubiese podido servir de base para un Estado nacional.

Este hecho no se debía sólo a la fragmentación espacial de las sociedades criollas, sino también a la heterogeneidad de las capas sociales y a las diferencias abismales que existían entre ellas (Lynch 1973: 339). En estas diferencias confluía la discriminación étnica racista y una gran desigualdad socio-económica entre ricos y pobres. La clase alta criolla, de piel blanca, no quería tener nada en común con la población de piel oscura que constituía el grueso de las capas sociales bajas y se cerraba sistemáticamente frente a éstas. Esta actitud de rechazo tenía su origen, por un lado, en un sentimiento de superioridad frente a la falta de educación y la alegada inferioridad de indios y negros. Por otro, se debía al temor a las revoluciones sociales, que se alimentaba entre otros motivos de la experiencia del levantamiento de Tupac Amaru en el Alto Perú, que había movilizado a un gran grupo de seguidores (Cornblit 1995).

El grupo de los blancos pobres, mestizos y mulatos que habían ascendido en la jerarquía social agudizaba las diferencias de clases en vez de mitigarlas, ya que éstos se iden-

7 No se ha tenido en cuenta en ella el elemento proletario en las ciudades ni los negros del sur. Además cabe destacar que la clase de los notables no apoyó en su totalidad la revolución, más bien un $20 \%$ adoptó la posición de la metrópoli. Estos loyalists emigraron en gran parte al Canadá. 
tificaban en gran medida con la clase blanca dominante. Tampoco se podía esperar que las clases bajas también divididas internamente hiciesen una contribución al diseño del orden político.

Asimismo, la clase alta era incapaz de ponerse de acuerdo sobre un proyecto coherente para la distribución de poder social y la organización política ya que estaba, a su vez, dividida (para la región del Plata véase Ferns 1973: 66). Los terratenientes conservadores, acostumbrados a estructuras jerárquicas, estaban en desacuerdo con los comerciantes de las ciudades costeñas, que eran liberales y abiertos a nuevas ideas. Mientras que los primeros le veían poco sentido a los principios republicanos de igualdad ante la ley y de división de poderes, los otros carecían de una base real de poder que les permitiese ganar apoyo y empuje para la implementación de sus ideas. Además se destacaba un tercer grupo, compuesto por intelectuales urbanos que redactaban y defendían las constituciones inspiradas por el espíritu de la Revolución Francesa y Norteamericana y que por su estrecha colaboración con la prensa emergente podrían describirse como los precursores de los políticos profesionales de hoy en día (Halperín Donghi 1972: 400; Garzón Valdés 1994: 49). Si bien ellos habían estudiado detenidamente el desarrollo de las constituciones europeas, carecían frecuentemente de conocimientos acerca de la realidad social de su propio país y sobre todo de las zonas rurales. ¿Cómo iban a poder enfrentar eficazmente la permanente intromisión de los militares en la vida política o movilizar el apoyo político que era necesario para hacer factible la implementación de sus proyectos constitucionales?

En las discusiones en torno a la consolidación de las instituciones democráticas y propias de un Estado de derecho en los países del tercer mundo se señala frecuentemente que es necesario un grado mínimo de homogeneidad de condiciones de vida para hacer efectiva la igualdad de derechos en las sociedades respectivas (Garzón Valdés 1999: 120; Tocqueville 1976: 284). Sin profundizar esta discusión se puede constatar que, en el momento de desligarse de España, América Latina estaba lejos de haber logrado este mínimo nivel de homogeneidad y cohesión social que hubiese sido necesario para posibilitar el éxito del proyecto republicano. No había burguesía, no había iniciativas de crear una sociedad civil que hubiesen podido llenar de vida los principios nobles de la constitución invocados en los documentos escritos.

\section{Función y percepción de la constitución}

Los diseñadores del nuevo orden político en América Latina se enfrentaban a un problema serio. Desde que la legitimación básicamente religiosa de la monarquía había sido sacudida por las dos grandes revoluciones, la norteamericana y la francesa, parecía casi imposible retornar al modelo de Estado monárquico. Mientras que los Estados tradicionalistas de Europa experimentaban con modelos en los cuales el monarca estaba debilitado y sometido a una constitución, esta alternativa era prácticamente inviable para los países latinoamericanos emergentes ${ }^{8}$ ¿ ¿De qué les habría servido conseguir un candidato

8 Hubo ocasionalmente intentos de ganar el apoyo de un monarca europeo para encabezar un Estado latinoamericano pero fracasaron siempre. 
europeo para el trono que desde el principio hubiese tenido que renunciar a la ventaja principal de la legitimación monárquica, el carisma de la herencia? Entre los modelos de Estado sólo quedaba una opción, la república. Sin embargo, en tanto en cuanto a estructura como mentalidad, las sociedades latinoamericanas no estaban preparadas para la construcción de repúblicas independientes. Como hemos visto, faltaban condiciones sociales tales como una cierta homogeneidad de los estilos de vida y de las condiciones económicas de ingreso y fortuna. Tampoco existía una clase dirigente político-intelectual que hubiese sido capaz de asumir esta tarea.

Los intelectuales y las personas interesadas en la política que se preocupaban por encontrar una futura forma de organización de Estado para sus sociedades tenían dos opciones: o bien tomaban en cuenta las condiciones sociales existentes, con su desigualdad social y su diversidad regional, tratando de encontrar la mejor solución posible; o bien sometían esta realidad deficiente en su opinión a constituciones liberales y progresistas con la esperanza de que a largo plazo la realidad social se adaptara al espíritu vanguardista con el que habían sido redactadas las leyes. El primer punto de vista contaba sobre todo con el apoyo de un grupo llamado conservador, mientras que los liberales apostaban al efecto transformador de la constitución. En muchos países las disputas entre estas dos fracciones políticas principales siguieron durante todo el siglo XIX (prolongándose más aún en algunos casos). Sin embargo, hay que tener en cuenta que las posiciones eran en algunos casos más flexibles de lo que sugiere la denominación programática respectiva, ya que a veces un partido cambiaba de bando según la constelación política.

De hecho, en la mayoría de los Estados latinoamericanos las constituciones diseñadas durante el siglo XIX se inspiraron en ideas liberales y republicanas, hecho que contrastaba -como hemos señalado anteriormente- con las formas concretas de ejercicio del poder. Luego de finalizada la larga etapa de las guerras civiles se produjo cierto desencanto que dio lugar, por ejemplo, a un manejo más restrictivo del derecho a voto y que hizo que se otorgaran facultades especiales al poder ejecutivo con el fin de garantizar el orden político (Lechner 1992: 81; Bushnell 1985: 147; Halperín Donghi 1991: 210). Sin embargo, en principio estos cambios no afectaron el optimismo ni la convicción de que con el pasar del tiempo la "verdadera" constitución formaría adecuadamente a las personas.

Tomemos el ejemplo de J. B. Alberdi, perteneciente a la ya mencionada Generación de 1837, que ideó la constitución argentina de 1853. De acuerdo con el proyecto de esta generación, según el cual la constitución debía corresponder más a la realidad social que las propuestas anteriores, la propuesta de Alberdi para el proyecto constitucional contenía una serie de observaciones y consideraciones acertadas acerca de la realidad sociopolítica de la región del Plata. Entre ellas, por ejemplo, que los ciudadanos aún no estaban lo suficientemente bien preparados para vivir en una república y que debían ser educados en este sentido; que la posición dominante de Buenos Aires era una desventaja para el Estado nacional que se pretendía fundar o que la diversidad y el particularismo regional característicos de la Argentina no dejaban otra opción que la creación de un Estado federal. Pero luego se impone su actitud utopista al declarar que las constituciones son herramientas de la civilización que deben facilitar sobre todo el desarrollo de un país y que por ello deben priorizar los asuntos técnicos frente a los humanos (Alberdi 1966: 18, 47). Según Alberdi, la constitución argentina debía cumplir las siguientes funciones: 
- Fomentar el desarrollo del país, sobre todo mediante una inmigración dirigida.

- Educar al soberano, es decir al pueblo, a que adopte una actitud republicana.

- Educar también a los gestores del poder estatal, es decir, acostumbrarlos al uso de las leyes a través de la concesión de generosos poderes, antes de convertir las leyes en instrumentos para controlar a estos mismos mandatarios.

Esta acumulación de funciones contrasta claramente con las metas que tenían en mente los padres de la constitución norteamericana de Filadelfia. Si bien en las constituciones de los Estados miembros se puede encontrar una diversidad de funciones parecida, los padres fundadores de la constitución federal tenían sobre todo una preocupación: buscaban encontrar un equilibrio entre la concentración del poder estatal y la garantía de la libertad individual. En otras palabras, pretendían conceder al individuo el mayor grado posible de libertad para actuar y desarrollarse sin que éste afectase seriamente la capacidad de funcionamiento de los órganos estatales (Adams 1973: 36). Éste era el sentido de las discusiones públicas, documentadas en los Federalist Papers y de los compromisos en parte originales ${ }^{9}$ que resultaron de las arduas negociaciones entre los que favorecían sólo la unión de los Estados miembros y aquellos que estaban a favor de un Estado federal, entre los que defendían la creación de un fuerte poder central y los que se oponían, dando preferencia a la división de poderes, a limitar los derechos del Estado central y a establecer un catálogo compuesto por una serie de derechos fundamentales.

Las llamativas diferencias sugieren que el norte y el sur de América diferían tanto en su percepción de la constitución como en la del hombre (en general Schneider 1987; Stourzh 1988). La literatura en torno a la propuesta de la constitución de 1787 evidencia que los padres fundadores norteamericanos eran sumamente críticos y escépticos en cuanto a la naturaleza del hombre (Botana 1991). Por un lado estaban de acuerdo con Montesquieu en que la virtud y el sentido común de los ciudadanos eran condición indispensable de la viabilidad de la república. Por otro, sin embargo, desconfiaban de las emociones incontrolables ya que éstas podían provocar fácilmente el abuso de poder en el caso de que éste se concentrase en pocas personas o también en una masa más grande de gente. La función esencial de las constituciones debía ser proteger al ciudadano individual y a la comunidad de estos abusos. Por ello, se otorgaba a las constituciones un rango especial que las colocaba por encima de las decisiones gubernamentales y parlamentarias así como de las simples leyes (Stourzh 1984: 168). Se opinaba que debían ser una especie de última garantía para el cumplimiento de los principios de justicia fundamentados en ellas, principios que debían poder ser invocados por cualquiera. A partir de esta percepción, se sobreentendía que las constituciones debían ser esencialmente intocables, circunstancia que no debía impedir una revisión parcial de sus contenidos con el fin de adaptarlos a nuevos desarrollos sociales.

Los padres de las constituciones latinoamericanas parecen haber tenido una imagen del hombre un tanto más positiva que los norteamericanos (aunque ésta se mezclaba con un tenor fatalista como nos demuestra el desprecio por los indios y en parte también por

9 Uno de los logros originales consistió en aplicar el modelo estatal republicano a un Estado gigante, pese a que debido a la influencia de Montesquieu se suponía que este modelo era adecuado sólo para pequeñas sociedades. Véase Botana (1991: 154). 
la "raza ibérica"). Asimismo, su interpretación acerca del sentido y de la finalidad que tienen las constituciones era un tanto más despreocupada. Si bien los fundadores de las constituciones latinoamericanas tenían en cuenta que el hombre comete errores, lo consideraban "bueno" tal como lo sugiere el pensamiento de Rousseau, o bien opinaban que era posible formarlo mediante la educación y las instituciones adecuadas. La elevada confianza que los padres de las constituciones latinoamericanas depositaban en el valor de la cultura y la educación hizo que le asignaran una función clave a las elites políticas e intelectuales para el desarrollo que sus países tenían que recuperar. La constitución debía ser un instrumento importante para este fin. Además, debía servir de reglamento para organizar el poder gubernamental y distribuir las atribuciones políticas y para poner límites al ejercicio del poder. Sin embargo, estas funciones eran consideradas secundarias con respecto a la principal, que consistía en anticipar el proyecto de un futuro orden político y social, en educar a los hombres para ese fin y en orientar el desarrollo hacia el mismo.

Es posible que estas distintas percepciones se hayan alimentado de diferentes tradiciones ideológicas. G. Stourzh ha señalado que además de la visión moderna proveniente de la filosofía política anglosajona que destaca la protección de los ciudadanos y los mecanismos de control del poder, existe una percepción más antigua con respecto a las constituciones. Según ésta, la constitución está simplemente compuesta por decretos y leyes dictados por la autoridad (Stourzh 1988: 43). ¿Sería posible que este concepto alternativo estuviera todavía presente en la mente de los fundadores de las constituciones latinoamericanas pese a los conocimientos que ellos tenían de las constituciones contemporáneas?

En todo caso, su concepción basada sobre todo en el carácter instrumental de la constitución, que se diferenciaba claramente de la de los fundadores de las constituciones norteamericanas, encerraba dos grandes riesgos. El primero resultaba del bajo valor propio que se le asignaba a la constitución al verla en primer lugar como un medio para un fin determinado. Los medios tienen que obedecer a sus fines respectivos y pueden ser cambiados por otros si no cumplen con el fin o si surge otro objetivo. Aquí radica posiblemente una de las razones por las cuales las constituciones han sido cambiadas tantas veces a lo largo de la historia política de muchos Estados latinoamericanos en el siglo XIX (y en parte también del siglo XX). El segundo riesgo está relacionado con la cuestión de cuál debe ser el objetivo específico que la constitución debe cumplir y quién lo define. En principio se trata de objetivos generales y nobles, como el progreso, el crecimiento, el bienestar de todos los ciudadanos u otras metas similares. ¿Cómo impedir que ciertos grupos y partidos se apoderen de los órganos constitucionales y del aparato legal con el fin de perseguir sus intereses particulares? El siglo XIX está lleno de ejemplos que demuestran que los grupos de poder han utilizado el Estado para imponer sus intereses especiales ${ }^{10}$. Dado que ni al Estado ni a la constitución se les atribuía un rango superior que debía ser respetado por todos, éstos quedaron fácilmente a merced de fuerzas rivales.

10 Las actitudes de los terratenientes de Venezuela y de la región del Plata en la primera mitad del siglo son un buen ejemplo de ello. Por un lado gobernaban sus haciendas sin preocuparse por las leyes. Por otro, sabían utilizar el Estado para sus propios intereses, logrando que se promulgasen leyes que limitaban el derecho de gauchos y llaneros a desplazarse libremente y que los obligaban a adoptar un puesto de trabajo fijo; en caso contrario corrían el riesgo de ser reclutados para el servicio militar (véase Lynch 1973: 343 y Halperín Donghi 1991:167). 


\section{Resumen}

Nuestro análisis comparativo puede ser leído desde varios puntos de vista. Puede entenderse como el intento de explicar la permanente inestabilidad política de América Latina en el siglo XIX, puede ser considerado como una contribución a la concepción particular que los latinoamericanos tienen del Estado o bien puede leerse como un comentario acerca de las deficiencias básicas que las condiciones institucionales ofrecían para el desarrollo económico del siglo pasado. Nosotros hemos querido mostrar sobre todo el condicionamiento histórico del trato ambiguo de las normas legales, comenzando por aquella norma básica, la constitución, que en realidad debía ser la norma que orienta a todas las demás. Se han identificado varias causas que han contribuido a que las constituciones de estos países no hayan alcanzado la importancia que le corresponde a la norma suprema que define los criterios para el reconocimiento de todas las demás normas legales, a saber:

- La adopción temprana de disposiciones liberales y progresistas en las constituciones promulgadas después de la independencia, que eran difícilmente compatibles con la realidad social y cuya implementación tenía que enfrentar dificultades (si realmente existía la intención seria de implementarla). De esta forma se cementó la base para un discurso ambiguo, que en el nivel retórico invocaba principios contra los cuales se atentaba permanentemente en la práctica.

- La creación temprana de dos formas de solucionar conflictos políticos, una civil y otra militar. La concesión de poderes especiales al poder ejecutivo y las prerrogativas de las fuerzas armadas institucionalizaron prácticamente el uso de medios violentos para imponer fines políticos. La habituación durante muchos años a la ambigüedad política ha dejado sus huellas en la conciencia colectiva y es difícil de cambiar.

- La tendencia a ver en la constitución un medio para alcanzar determinadas metas político-sociales. Si bien en el comienzo esto había sido concebido en vistas del logro de fines superiores, esta interpretación de la constitución (así como de las leyes que derivan de ella) puede dar fácilmente lugar al abuso por parte de intereses particulares.

No afirmamos que los factores aquí presentados hayan sido la principal y única causa de la actitud ambigua que muchos latinoamericanos manifiestan en el trato que le dan al derecho y a las leyes. Sin embargo, lo que sí se puede constatar es que al fundar los nuevos Estados no se supo aprovechar la oportunidad que se ofrecía en ese momento para combatir un mal antiguo.

Si bien este estudio ha estado principalmente estructurado por el análisis de los contrastes que existen entre los EE.UU. y América Latina, no se deberían sobrestimar las diferencias entre ambos, sobre todo en cuanto a la actitud frente al derecho y a las leyes. También en los EE.UU., la obediencia a la ley tenía sus limites; la corrupción, por ejemplo, era y sigue siendo más que un problema endémico tanto en América del Sur como del Norte (Gardiner/Olson 1974). En ambos casos el Estado nunca ha logrado imponer el monopolio del empleo legítimo de la violencia física (Grahan/Gurr 1969). Sin embargo, en los EE.UU. las desviaciones del Estado legal se limitan a ámbitos e instituciones de 
segunda categoría. A diferencia de América Latina, los órganos estatales y la estructura de organización política en su totalidad nunca han sido afectados. Esto se debe probablemente también al éxito del proceso que condujo a la creación de la constitución en su fase fundadora y que se destaca de forma positiva respecto de los procesos análogos que tuvieron lugar pocos años después en América Latina.

\section{Bibliografía}

Adams, Willi Paul (1973): Republikanische Verfassung und bürgerliche Freiheit. Die Verfassungen und politischen Ideen der amerikanischen Revolution. Darmstadt/Neuwied.

Alberdi, Juan Bautista (1966): Bases y puntos de partida para la organización política de la República Argentina. Buenos Aires.

Bernecker, Walther L. et al. (eds.) (1992): Handbuch der Geschichte Lateinamerikas, vol. 2: Lateinamerika von 1760 bis 1900. Stuttgart.

Boeckh, Andreas (1998): Lateinamerikanische Entwicklungsvorstellungen zwischen Nachahmung und Eigenständigkeit: Historische Erfahrungen und künftige Perspektiven. Tubingia: Manuscrito.

Botana, Natalio R. (1991): “La Convención de Filadelfia de 1787”. En: ídem: La Libertad Política y su Historia. Buenos Aires, pp.149-171.

Buisson, Inge (1992): "Probleme der Staatenbildung im spanischen Südamerika (1810-1830)". En: Elvert, Jürgen; Salewski, Michael (eds.): Staatenbildung in Übersee. Stuttgart, pp. 11-20.

Bushnell, David (1985): "The Independence of South America". En: Bethell, Leslie (ed.): The Cambridge History of Latin America, vol. III. Cambridge, pp. 95-156.

Constitución y Leyes Políticas de la Republica de Chile. Santiago 1881.

Constitución de Estado Bolivar. Caracas 1864.

Constituciones Políticas del Perú 1821-1919. Lima 1922.

Cornblit, Óscar (1995): Power and Violence in the Colonial City. Cambridge.

Criscenti, Joseph T. (1961): "Argentine Constitutional History, 1810-1852: A Re-Examination". En: HAHR, vol. 41, pp. 367-409.

Chiaramonte, José C. (1986): "Legalidad constitucional o caudillismo: El problema del orden social en el surgimiento de los Estados autónomos del litoral argentino en la primera mitad del siglo XIX”. En: Desarrollo Económico, 102 (julio-septiembre), pp. 175-196.

Fairfield, Roy P. (ed.) (1986): The Federalist Papers. Baltimore/Londres, $2^{\mathrm{a}}$ edición.

Ferns, Henry Stanley (1973): La Argentina. Buenos Aires.

Fisher, John R. (1992): "Iberische Kolonialpolitik seit 1760". En: Bernecker, Walter et al. (eds.): Handbuch der Geschichte Lateinamerikas, Vol. 2: “Lateinamerika von 1760 bis 1900”. Stuttgart, pp. 15-63.

Galvão de Sousa, Jose P. (1967): "Remarques sur l'idée de constitution et la signification sociologique du droit constitutionnel". En: Jahrbuch des öffentlichen Rechts, vol. 10, pp. 39-66.

Gardiner, John A.; Olson, David J. (eds.) (1974): Theft of the City. Readings on Corruption in Urban America. Bloomington/Londres.

Gargarella, Roberto (2000): "The Scepter of Reason. Public Discussion and Political Radicalism in the Origins of Constitutionalism". Manuscrito.

Garzón Valdés, Ernesto (1994): "Verfassung und Stabilität in Lateinamerika". En: Innsbrucker Geographische Studien, vol. 21, pp. 43-60.

- (1999): "Rechtsphilosophische Überlegungen über Verfassungsreformen in Lateinamerika". En: Ahrens, Helen/Nolte, Detlefs (eds.): Rechtsreformen und Demokratieentwicklung in Lateinamerika. Francfort, pp. 110-133. 
Gebhard, Jürgen (1999): “Amerikanismus - Politische Kultur und Zivilreligion in den USA”. En: Aus Politik und Zeitgeschichte, B49/90, 30.11.1999, pp. 3-18.

Graham, Hugh Davis; Gurr, Ted R. (eds.) (1969): The History of Violence in America. Nueva York (Washington), Londres.

Gumucio, Mariano Baptista (1987): Latinoamericanos y norteamericanos. Cinco siglos de dos culturas. La Paz.

Halperín Donghi, Tulio (1972): Revolución y guerra. Formación de una élite dirigente en la Argentina criolla. Buenos Aires.

- (1991): Geschichte Lateinamerikas von der Unabhängigkeit bis zur Gegenwart. Francfort.

Hart, Herbert Lionel (1961): The Concept of Law. Oxford.

Heideking, Jürgen (1989a): "Die demokratische Herausforderung. Revolution, Unabhängigkeitskrieg und Bundestagsgründung in Nordamerika, 1763-1815”. En: Langewiesche, Dieter (ed.): Revolution und Krieg. Zur Dynamik historischen Wandels seit dem 18. Jahrhundert. Paderborn, pp. 33-55.

- (1989b): "Die geschichtliche Bedeutung der amerikanischen Verfassungsdebatte von 1787 bis 1791”. En: Amerikastudien, 34, pp. 33-48.

- (1999a): "Ableger' Europas oder historischer Neubeginn? Britisch-Amerika und die USA". En:. Reinhard, Wolfgang (ed.): Verstaatlichung der Welt? Schriften des Historischen Kollegs: Kolloquien 47. Munich, pp. 1-18.

- (1999b): "People's War or Standing Army? Die Debatte über Militärwesen im Krieg in den Vereinigten Staaten von Amerika im Zeitalter der Französischen Revolution”. En: Kunisch, Johannes/Münkler, H. (eds.): Die Wiedergeburt des Krieges aus dem Geist der Revolution. Berlín, pp. 131-152.

Lechner, Jan (1992): “Kultur und Literatur". En: Bernecker, Walter et al. (eds.): Handbuch der Geschichte Lateinamerikas, vol. 2: Lateinamerika von 1760 bis 1900. Stuttgart, pp. 64-92.

Loveman, Brian (1993): The Constitution of Tyranny. Regimes of Exception in Latin America. Pittsburgh/Londres.

Lucena Salmoral, Manuel (1992): "Neu-Granada/Großkolumbien”. En: Bernecker, Walther et al. (eds.): Handbuch der Geschichte Lateinamerikas, vol. 2: Lateinamerika von 1760 bis 1900. Stuttgart, pp. 208-248.

Lutz, Donald S. (1988): The Origins of American Constitutionalism. Baton Rouge y Londres.

Lynch, John (1973): The Spanish American Revolutions 1808-1826. Londres.

- (1985): "The Origins of Spanish American Independence". En: Bethell, L. (ed.): The Cambridge History of Latin America, vol. III. From Independence to 1870. Cambridge, pp. 3-49.

Mann, Michael (1993): The Sources of Social Power, vol. II: The rise of classes and nation-states, 1760-1914. Cambridge.

Nohlen, Dieter (1994): “Vergleichende Methoden”. En: ídem (ed.): Lexikon der Politik. Munich, vol. 2, pp. 507-517.

North, Douglas et al. (1983): Growth and Welfare in the American Past. A new Economic History. Englewood Cliffs.

Puhle, Hans-Jürgen (1994): "Unabhängigkeit, Staatenbildung und gesellschaftliche Entwicklung in Nord- und Südamerika". En: Junker, Detlef et al. (eds.): Lateinamerika am Ende des 20. Jahrhunderts. Munich, pp. 27-48.

Riekenberg, Michael (1995): Nationbildung. Sozialer Wandel und Geschichtsbewußtsein am Rio de la Plata (1810-1916). Francfort.

Rodríguez, Jaime E. (1998): The Independence of Spanish America. Cambridge (reprint).

Romero, Jose Luis (1969): Las Ideas Politicas en Argentina. Buenos Aires.

Schneider, Hans (1987): “Konstitutionalismus". En: Evangelisches Staatslexikon. Stuttgart, $3^{\mathrm{a}}$ edición, rubro 1860 y ss. 
Schröter, Bernd (1992): "Überlegungen zu Alternativen der gesellschaftlichen Entwicklung in Spanisch-Amerika am Ende der Kolonialzeit (1770 bis 1820/24)". En: Asien Afrika Lateinamerika, vol. 20, pp. 133-140.

Stourzh, Gerald (1984): "The American Revolution, Modern Constitutionalism and the Protection of Human Rights". En: Thompson, K./ Myers, R. J. (eds.): Truth and Tragedy. A Tribute to Hanns J. Morgenthau. New Brunswick/Londres, pp. 162-175.

- (1988): "Constitution. Changing Meanings of the Term From the Early Seventeenth to the Late Eighteenth Century". En: Ball, T.; Pocock, J. G. (eds.): Conceptual Change and the Constitution. Kansas, pp. 35-54.

Tobler, Hans Werner (2000): "Die Staatsentwicklung in den USA und Lateinamerika". En: Edelmayer, F. et al. (eds.): Die vielen Amerikas. Die Neue Welt zwischen 1800 und 1930. Francfort, pp. 53-68.

Tocqueville, Alexis de (1976): Über die Demokratie in Amerika. Munich.

Vallenilla Lanz, Laureano (1961): Cesarismo democrático. Estudios sobre las bases sociológicas del la constitución efectiva de Venezuela. Caracas, $4^{\mathrm{a}}$ edición ( $1^{\mathrm{a}}$ edición 1919).

Vorländer, Hans (1989): "Verfassungsverehrung in Amerika: Zum konstitutionellen Symbolismus in den USA". En: Amerikastudien, 34, pp. 69-82.

Vorländer, Hans (1997): Hegemonialer Liberalismus. Politisches Denken und politische Kultur in den USA. Francfort/Nueva York.

Waldmann, Peter (1971): "Vergleichende Analyse autoritärer Staatsideologien in Lateinamerika". En: Lindenberg, Klaus (ed.): Politik in Lateinamerika. Hannover, pp. 33-44.

- (1978): “Caudillismo als Konstante der Politischen Kultur Lateinamerikas?”. En: Jahrbuch für Geschichte von Staat, Wirtschaft und Gesellschaft Lateinamerikas, vol. 15, pp. 191-208.

Werz, Nikolaus (1991): Das neuere politische und sozialwissenschaftiche Denken in Lateinamerika. Freiburg. 